\title{
DECISION MAKING ON OPTIMAL ROAD SUBNETWORK
}

\author{
Jan Černý1 ${ }^{\text {, Anna Černá }}{ }^{2}$, Vladimír Přibyl ${ }^{3}$ \\ ${ }_{1,2,3}$ University of Economics, Prague, Faculty of Management, Jindřichưv Hradec, Czech Republic
}

Received 20 November 2012; accepted 16 December 2012

\begin{abstract}
The paper introduces a family of subnetwork optimization problems as a part of network management theory. Three optimization problems are formulated and the solution methods are described. Five practical situations, when these solutions may be applied, are presented. Possibilities of future research are outlined as well.
\end{abstract}

Keywords: transport network, subnetwork, cost, length, attractiveness, optimization.

\section{Introduction}

This paper presents topics met during the last decade by the Research Group of Network Management and Optimization at the Faculty of Management of the University of Economics in Prague. The main purpose of the paper is to show how the transport network theory can help managers of public administration or of carriers in their decision making on the optimal subnetwork choice. Examples of the possible practical situations are mentioned in the chapter 2 .

The problems, the paper deals with, belong to network economy theory. This scientific discipline contains several branches. They can be divided into two main directions: The first one focuses networks of mutually connected and interacting enterprises, as described e.g. in the books by Fiala (2008) or DeMan (2004). The second direction looks for economically optimal transport and telecommunication networks as described e.g. in the papers by Jun Xiao et al. (2008) and Shimoda (2000).

The later contains, among others, the family of network design problems, namely the ones looking for a subnetwork of the given network. Several papers deal with related topics, concerning a network, represented by a graph $G=(V, E, c)$ with $c(e) \geq 0$ expressing a general cost (e.g. passing time, length, building cost, toll etc.) of the edge $e \in E$. The paper by Eades et al. (1982) seeks the maximum planar subgraph of $G$. The papers by Cheriyan and Thurimella (2000) or by Gabow et al. (2005) seek a $\lambda$-edge connected spanning subgraph which minimizes costs of edges when the integer $\lambda>0$ is given. Minimization of total edge costs is also the topic of the papers by Safari and Salavatipour (2008), Amini et al. (2009) and Vassilevska et al. (2006). Other papers deal with maximum cost subgraphs, namely Suzuki and Tokuyama (2006) and Amini et al. (2009).

The problems studied in the present paper look for a subgraph, analogically as the items mentioned above. However, the constraint and objective functions are different. They are formulated precisely in the chapter 3 .

Particular cases of the problems are met when the subgraph is linear, i.e. it forms a route. Note that it is not necessary that the route is a path in mathematical sense. It may happen that the route arrives to a vertex $v$, then it

${ }^{1}$ Corresponding author: cerny@fm.vse.cz 
deviates to a vertex $u$, returns back to $v$ and continues in its original direction.

\section{Examples of Applications}

In practice, it is quite often possible to meet managerial decision problems concerning the selection of optimal subnetwork of the given network. In the sequel, some typical ones are mentioned.

\subsection{Rural Road Network}

In the Czech Republic, one can see many regions with the average distance about $2 \mathrm{~km}$ between neighboring villages. There are direct roads from a village to other 3,4 or 5 villages. Such a network is too large for the maintenance, especially in the winter time. The problem is to find a suitable subnetwork. It is necessary not to increase significantly the length of trips between villages.

\subsection{New Urban Transport in Sprawl Zones}

There are many sprawl zones around or within metropolitan areas. The zones are covered by networks of local roads, more or less suitable for the operation of buses, at least the smaller ones. The problem of public administration (and, maybe, together with carriers) is to choose a bus routes subnetwork of the given network. The problem has different variants, depending on whether the network is chosen freely, or whether there are predetermined vertices, such as railway station, subway station, etc.

\subsection{Urban Trolleybus or Tram Network}

It happens that an existing bus network is to be partially transformed to a trolleybus (or a tram) network. The decision problem is to choose the corresponding subnetwork to be electrified.

\subsection{Urban Bus Transport Intensification}

It may happen that the bus transport system in a town is "extensive", i.e. it consists of many routes with long headways, operating on very dense road network. Almost all streets are passed by a bus route, but the passengers there have to wait for the next connection for a long time. If one wants to intensify it without increasing of costs, the existing network must be reduced to a suitable subnetwork.

\subsection{Leisure Non-Motorized Network}

This problem is met when, in a nature area, there is a network of natural, soft (i.e. unpaveed) surface field and forest paths and a trail subnetwork for hiking or leisure cycling is to be chosen. Afterwards, in case of hiking, the trails are marked and all places of impassability are eliminated. In the case of cycling, the trails are hardened, usually bituminized in the width allowing two-way traffic.

\section{Constraints and Objectives}

Suppose that a network $G=(V, E)$ and its subnetwork $G^{\prime}=\left(V^{\prime}, E^{\prime}\right)$ are given, i.e. $V^{\prime} \subset V$, $E^{\prime} \subset E$. Then the following functions could be done:

$\begin{aligned} q: V \rightarrow\langle 0 ; \infty) \quad & \text { where } q(v) \text { denotes the } \\ & \text { passenger demand a hour } \\ & \text { in the edge } v, \\ & \text { where } t(e) \text { denotes the } \\ & \text { duration of transit through } \\ & \text { the edge } e, \\ & \text { where } d(e) \text { denotes the } \\ & \text { length of the edge } e, \\ & \text { where } c(e) \text { denotes the } \\ & \text { cost (maybe generalized) } \\ & \text { associated e.g. with the } \\ & \text { construction or maintenance } \\ & \text { of the edge } e,\end{aligned}$


$a: V \cup E \rightarrow\langle 0 ; \infty)$ where $a(v)$ or $a(e)$ denote the tourist attractiveness of passing through the vertex $v$ or through the edge $e$ respectively.

Remark. If $r=v_{0}, e_{1}, v_{1}, e_{2}, v_{2}, \ldots, e_{n}, v_{n}$ is a route then $r$ is said the route connecting $v_{0}$ and $v_{n}$ and

$$
\begin{aligned}
& t(r)=t\left(e_{1}\right)+t\left(e_{2}\right)+\ldots+t\left(e_{n}\right) \text { expresses } \\
& \text { the passing time of the route } r,
\end{aligned}
$$
$d(r)=d\left(e_{1}\right)+d\left(e_{2}\right)+\ldots+d\left(e_{n}\right)$ expresses the length of the route $r$, $c(r)=c\left(e_{1}\right)+c\left(e_{2}\right)+\ldots+c\left(e_{n}\right)$ expresses the costs of the route $r$, $a(r)=a\left(e_{1}\right)+a\left(v_{1}\right)+\rho a\left(e_{2}\right)+\rho a\left(v_{2}\right)$ $+\ldots++\rho a\left(e_{2}\right)+\rho a\left(v_{n}\right)$ expresses attractiveness of the route $r$, where the reduction factor $\rho=1$ when corresponding vertex or edge is passed for the first time and $\rho<1$ (e.g. $\rho=0.2$ ) otherwise.

Remark. The minimal possible length of the route connecting two vertices $v$ and $w$ is the distance $d(v, w)$ of $v$ and $w$. Obviously, the shortest route connecting two vertices $v \neq w$ is a path, because it certainly does not pass twice through any its vertex. As one will see, all problems presented in the sequel have their constraint and objectives formulated exclusively in terms of the functions $q, t, d$, $\mathrm{c}$ and $\mathrm{a}$.

\section{Selected Problems}

The following problems correspond to the examples mentioned in the chapter 2 (not one-to-one, of course).

\subsection{The Cheapest Subnetwork with Limited Relative Extension of Distances}

Suppose a network $G=(V, E, d)$ is given, together with a set $W \subset V \times V$ of important pairs and a number $\psi \in\langle 1 ; \infty)$ expressing the relative extension limit. The problem is to find a subnetwork $G^{\prime}=\left(V^{\prime}, E^{\prime}, d^{\prime}\right)$ with the property that

$d^{\prime}(e)=d(e)$ for all $e \in E^{\prime}$ fulfilling the constraint

$d^{\prime}(v, w) \leq \psi^{*} d(v, w)$ for all $v, w \in W$ and minimizing the total length of $E^{\prime}$

$$
d\left(E^{\prime}\right)=\sum_{e \in E^{\prime}} d(e) \rightarrow \min
$$

Remark. It is shown in Czimerman et al. (2007) that in the particular case of $\psi=1$ the problem is NP-hard and it would be very surprising if for $\psi>1$ it is not.

Remark. The problem 4.1 corresponds to the examples 2.1 and 2.4 .

Solution. The authors were quite successful in solving this problem optimally (in smaller instances) as by depth-first-search as by integer linear programming and (in greater instances) by an original heuristics. The paper describing these results will be completed soon.

\subsection{The Cheapest Subnetwork with Limited Inaccessibility of Bus Service}

Suppose a network $G=(V, E, d)$ is given, together with the inaccessibility limit $\lambda \in\langle 0 ; \infty)$ and the passenger demand $q(v)$ for each vertex $v \in V$. Let

$$
Q=\sum_{v \in V} q(v)
$$

denote the total number of passengers in the network and for $V^{\prime} \subset V$

$$
d\left(v, V^{\prime}\right)=\min \underset{w \in V^{\prime}}{d(v, w)}
$$


is the distance of a vertex $v \in V$ from the closest vertex $w \in V^{\prime}$.

The problem is to find a bus service subnetwork $G^{\prime}=\left(V^{\prime}, E^{\prime}, d^{\prime}\right)$ with the property that the mean walking distance to the next stop, expressing "inaccessibility", should not exceed the limit, i.e.

$$
\frac{1}{Q} \sum_{v \in V} q(v) d\left(v, V^{\prime}\right) \leq \lambda
$$

and the costs ought to be minimal:

$$
\sum_{v \in V} c(v) \rightarrow \min
$$

Remark. The problem 4.2 corresponds to the examples 2.2 and 2.3. The resulting subnetwork $G^{\prime}$ is then the basis for the construction of bus/trolleybus routes. However, that is outside the scope of this paper. An exception is when $G^{\prime}$ is linear, i.e. when it represents a route itself.

Solution. For the case when it is requested that the subgraph $G^{\prime}$ should be linear, i.e. that it represents a route, the exact methods depth-search-first and integer linear programming are described in the paper by Černá et al. (2011), together with several heuristics. The general case may be solved by a modification of depth-first-search method and the heuristics.

\subsection{The Most Attractive Route for Cyclists or Hikers}

Suppose a network $G=(V, E, d, c, a)$ is given, together with two important vertices $v \in V$, $w \in V$, the length limit $\lambda \in(0 ; \infty)$ and the cost limit $\gamma \in(0 ; \infty)$. The problem is to find a route $r=v_{0}, e_{1}, v_{1}, e_{2}, v_{2}, \ldots, e_{n}, v_{n}$ such that $v_{0}=v, v_{n}=w$ meeting the constraints

$$
c(r) \leq \gamma, \quad d(r) \leq \lambda
$$

and maximizing the objective function

$$
a(r) \rightarrow \max
$$

Remark. The problem 4.3 corresponds to the example 2.5.

Solution. The depth-first-search method can be found in the paper by Černá and Černý (2012). The integer linear programming and heuristics are subject of research.

\section{Conclusion}

The paper presented practical situations when managers of public administration and of carriers are faced with a problem to find an optimal subnetwork of the given transport network. Three different optimization problems were formulated and possible methods for exact and heuristic solution are presented (if they are known). The open questions are also outlined. One can expect the following direction of the future research:

- exact and heuristic solution of the general case of the problem 4.2;

- direct imbracement of route design into the problem 4.2;

- integer linear programming and efficient heuristics for the problem 4.3 where one of the difficulties is in the attractiveness reduction when an edge or a vertex are passed for the second time.

\section{Acknowledgements}

The described research was supported by the Czech Scientific Agency GAČR project No. 402/12/2147 "Economically Optimal Processes on Networks". 


\section{References}

Amini, O.; Peleg, D.; Pérennes, S.; Sau, I.; Saurabh, S. 2009. Degree-Constrained Subgraph Problems: Hardness and Approximation Results. In: E. Bampis and M. Skutella (Eds.): WAOA 2008, LNCS 5426, Springer-Verlag, Berlin Heidelberg. 29-42.

Černá, A.; Černý, J. 2012. Note on Optimal Paths for Non-Motorized Transport on the Network. In Proceedings of the 30th International Conference Mathematical Methods in Economics, Karviná, Czech Republic. 91-94.

Černá, A.; Černý, J.; Přibyl, V. 2011. Bus Route Design in Small Demand Areas, Transport. DOI: http://dx.doi. org/10.3846/16484142.2011.622135, 26(3): 248-254.

Cheriyan, J.; Thurimella, R. 2000. Approximating Minimum-Size k-Connected Spanning Subgraphs via Matching, SIAM Journal on Computing, 30(2): 528-560.

Czimerman, P.; Černá, A.; Černý, J.; Peško, Š. 2007. Network Reduction Problems, Journal of Information, Control and Management Systems, 5(2): 139-147.

De Man, A.P. 2004. The Network Economy: Strategy, Structure and Management. Edw. Elgar, Cheltenham, G.B. 190 p.

Eades, P.; Foulds, L.R.; Giffin, J.W. 1982. An Efficient Heuristic for Identifying a Maximum Weight Planar Subgraph. Combinatorial Mathematics IX, Lecture Notes in Mathematics No. 952, Springer-Verlag, Berlin Heidelberg. 239-251.

Fiala, P. 2008. Network Economics (in Czech). Professional Publishing, Praha. 324 p.

Gabow, H.N.; Goemans, M.X.; Tardos, E.; Williamson, D.P. 2005. Approximating the Smallest k-Edge Connected Spanning Subgraph by LP-Rounding. In SODA '05 Proceedings of the sixteenth annual ACM-SIAM symposium on Discrete algorithms. Society for Industrial and Applied Mathematics Philadelphia, PA, USA. 562-571.
Xiao, J.; Cui, Y.; Luo, F.; Liu, M.; Wang, J.; Li, Y.; Gao, Y.; Wang, S. 2008. Comprehensive method on evaluation of distribution network planning. In Proceedings of the Third International Conference on Electric Utility Deregulation and Restructuring and Power Technologies, Nanjuing, China. 1249-1254.

Safari, M.A.; Salavatipour, M.R. 2008. A Constant Factor Approximation for Minimum $\lambda$-Edge-Connected k-Subgraph with Metric Costs. In: A. Goel et al. (Eds.): APPROX and RANDOM 2008, LNCS 5171, Springer-Verlag, Berlin Heidelberg. 233-246.

Shimoda, Y. 2000. Heat source network and heat transport, District Heating \& Cooling, 41(3): 3-5.

Suzuki, A.; Tokuyama, T. 2006. Dense subgraph problem revisited. In Proceedings of the Joint Workshop "New Horizons in Computing" and "Statistical Mechanical Approach to Probabilistic Information Processing", Sendai, Japan. 1-2.

Vassilevska, V.; Williams, R.; Yuster, R. 2006. Finding the Smallest H-Subgraph in Real Weighted Graphs and Related Problems. In: M. Bugliesi et al. (Eds.): ICALP 2006, Part I, LNCS 4051, Springer-Verlag, Berlin Heidelberg. 262-273.

\section{MODELIRANJE OPTIMALNE PUTNE MREŽE ZASNOVANO NA METODAMA ODLUČIVANJA}

\section{Jan Černý, Anna Černá, Vladimír Přibyl}

Sažetak: U radu je predstavljena grupa problema podmrežne optimizacije kao deo teorije upravljanja mrežama. Za potrebe istraživanja, formulisana su tri problema optimizacije i detaljno su opisane metode rešavanja. Takođe, predstavljeno je pet praktičnih situacija u kojima se ova rešenja mogu primeniti i dat je pregled budućih istraživanja.

Ključne reči: transportna mreža, podmreža, troškovi, dužina, atraktivnost, optimizacija. 